\title{
THE FABRICATION OF QUADRUPOLE MAGNETS FOR PEP-II LER
}

\author{
Fuhe Huang, Yaolin Sun, Xiaoping Wang, Dunan Zhang, Bingsong Huang, Lan Dong \\ (IHEP, Beijing, China)
}

\section{Abstract}

There are eight types of precision quadrupole magnets, total 320 for the PEP-II Low Energy Ring (LER) of SLAC B factory project. For this job, IHEP utilized some special technical measures, fabricated more than 40 types (about 70 sets) of precision technical equipment, fixtures and specially tooling. A highprecision die-set has been made which punched 560 thousand of laminations successfully. By the end of April of 1997309 qualified quadrupole magnets have been completed.

\section{INTRODUCTION}

A total of 320 PEP-II LER quadrupole magnets which are designed by LBNL in collaboration with IHEP are being fabricated by the IHEP machine-shop. The fabrication began in December, 1994, and the prototype magnet was finished in July 1995. Currently, 309 quadrupole magnets have been completed; 261 of them have been shipped from IHEP to LBNL. The magnetic measurement of all magnets is carried out by IHEP, and some measurements are repeated by LBNL. The results show that all magnets satisfy the prescribed specifications.

The LER Quadrupoles are divided among eight types (Table 1); they have the same contour size: $461 \mathrm{~mm} \times 646 \mathrm{~mm} \times 617 \mathrm{~mm}$, and the weight of each is about $1,200 \mathrm{~kg}$.

Table 1. Quantity of Each Type of Magnet

\begin{tabular}{|c|c|c|c|c|c|c|c|}
\hline Type & QTY & QF & QD & A & B & C & D \\
\hline Q43-15-Al-1 & 150 & 77 & 73 & 77 & 73 & & \\
\hline Q43-58-Al-1 & 4 & 2 & 2 & & 2 & 2 & \\
\hline Q43-58-Al-2 & 16 & 6 & 10 & & 4 & 8 & 4 \\
\hline Q43-58-Al-4 & 87 & 44 & 43 & 3 & 1 & 70 & 13 \\
\hline Q43-58-Cu-2 & 13 & 8 & 5 & & & & 13 \\
\hline Q43-58-Cu-4 & 18 & 7 & 11 & & & & 18 \\
\hline Q43-52-Al-4 & 12 & 120 & & & & & 12 \\
\hline Q43-52-AL-8 & 20 & 8 & 12 & & & & 20 \\
\hline TOTAL & 320 & 164 & 156 & 80 & 80 & 80 & 80 \\
\hline
\end{tabular}

The fabrication precision requirements are very high. The gap requirement between the adjacent pole tips is $34.88+1-0.05 \mathrm{~mm}$; the deviation of the magnetic center with respect to the mechanical center must be less than $0.05 \mathrm{~mm}$; the dispersion of the effective length between magnets must be less than or equal to $1 \times 10^{-3}$. Details of the quadrupole magnets design are reviewed in an earlier paper [1].
To fulfill this mission in high quality and speed professionally, IHEP machine shop set up a production line and laid down a technological process which was approved by LBNL; meticulously designed and fabricated a variety of tooling; set up a Quality Control and Quality Assurance system according to ISO 9000 standard.

\section{TOOLING}

To assure the production quality and consistency, 40 types (about 70 sets) of precision technical equipment, fixtures and tooling were designed and fabricated including punching die-set for core laminations, core lamination stacking fixtures, coil epoxy potting molds, end-pack stacking \& curing fixtures, pole tip chamfer machining fixtures, end plate machining fixture, drilling fixtures, welding fixtures, bussing bending fixtures, lifting tooling for core handling and so on. The production practice shows that all these tooling components play very important roles in QA and QC. It is worth mentioning that the punching die set has a high precision and long life. The total 560,000 laminations for the 320 magnets have been punched with one set of punching die set. All the laminations satisfy the uniformity requirement 0.02 $\mathrm{mm}$ and the burr requirement $0.03 \mathrm{~mm}$ (Fig.1). This is the first time for IHEP to have made this kind of punching die set that has such a long life in practice.

\section{CORE FABRICATION}

The shuffling process is a very important program to assure the reproducibility of magnets. The method we adopt is to distribute the laminations punched from different packets of steel sheet with different magnetic properties to each half core and to distribute the laminations punched early and late to each half core.

Stacking is a key process. We control the half core weight difference among magnets in the range not to exceed the weight of one lamination $(\approx 500 \mathrm{~g})$. Stacking pressure is more than $3 \mathrm{~kg} / \mathrm{cm}^{2}$. Stacking factor is more than $97.5 \%$. The geometrical sizes of every half core are controlled strictly. For instance, the flatness of yoke and pole is less than $0.03 \mathrm{~mm}$ (the design requirement is $0.05 \mathrm{~mm})$. The length deviation of half core is within the range of $+0.25 \mathrm{~mm}$ to $-0.13 \mathrm{~mm}$ (the design requirement is $+/-0.50 \mathrm{~mm}$ ).

Welding the core is the last key process for the half core fabrication. We adopt a reasonable welding standard, and the welding deformation is less than $0.02 \mathrm{~mm}$. 
Until now, among the 638 half cores (for 319 magnets) the rate of finished products is $100 \%$.

\section{COIL FABRICATION}

The coil fabrication is very complicated. Among the procedures, the vacuum impregnation procedures are the most important and key ones. For the LER Quadrupoles, we adopt the potting procedures which were used for BEPC project in 1980's. The production practice shows that the procedures can satisfy the requirements well. The main difference of these procedures from the procedures which were used by LBNL, is the different potting mold design. Our mold design uses the mold itself as the vacuum sealing container; LBNL's mold was placed separately into a big vacuum tank.

There are four kinds of coils; they are as follows:

\begin{tabular}{|c|c|c|c|c|}
\hline Material & Cross Sec. & W Channel & Turns & W Circuits \\
\hline & (inch) & (ID inch) & & \\
\hline $\mathrm{Al}$ & $0.5 \times 0.5$ & 0.25 & 15 & 1 \\
\hline $\mathrm{Al}$ & $.25 \times .25$ & 0.124 & 58 & $1,2,4$ \\
\hline $\mathrm{Al}$ & $.25 \times .25$ & 0.124 & 52 & 4,8 \\
\hline $\mathrm{Cu}$ & $.25 \times .25$ & 0.124 & 58 & 2,4 \\
\hline
\end{tabular}

During the fabrication of coils, some coil cracking occurred. After we found the causes we have solved the problem. There are several main causes that made some coils crack.

1. The thickness of epoxy at the root of the coil lead is too thick. When we open the mold after potting and curing, the outer force makes the thick epoxy at the lead root crack.

2. The contour size of the wound coil is too big, and it caused difficulty in putting the coil into mold. After we forced the coil into the mold, the coil accumulated some stress. When the potted coil was taken out of the mold, the stress releases caused the epoxy to crack.

\section{MAGNET ASSEMBLY}

The gaps between the pole tips of upper half core and low half core are adjustable with shims.

When we carry out the pre-assembly, we chose two half cores which have similar lengths, adjust the gaps within the tolerance $(+/-0.04 \mathrm{~mm})$, and ensure the clamp torque of the two half cores is identical with others.

Last, we assemble all the parts including the four coils, bussing, water hose, and so on, and remeasure the gaps precision as mentioned above.

So far, all the quadruple magnets we produced satisfy the specifications [ see Figure 2, 3, 4 and 5].

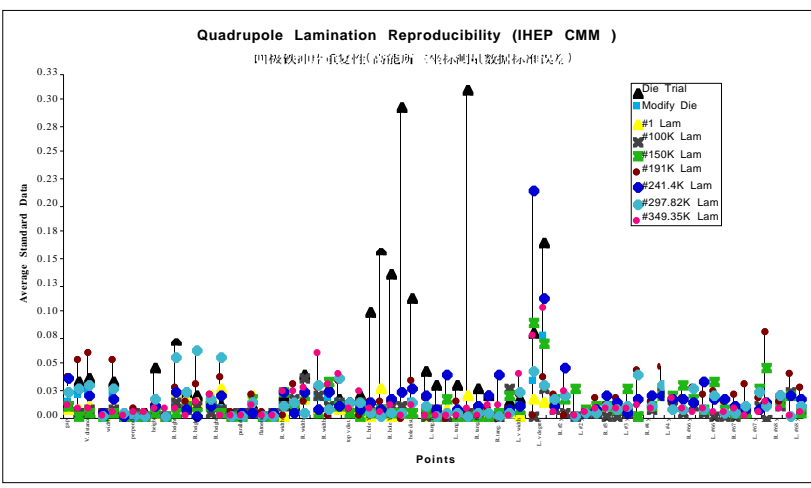

Figure 1: Quadrupole Lamination CMM Data

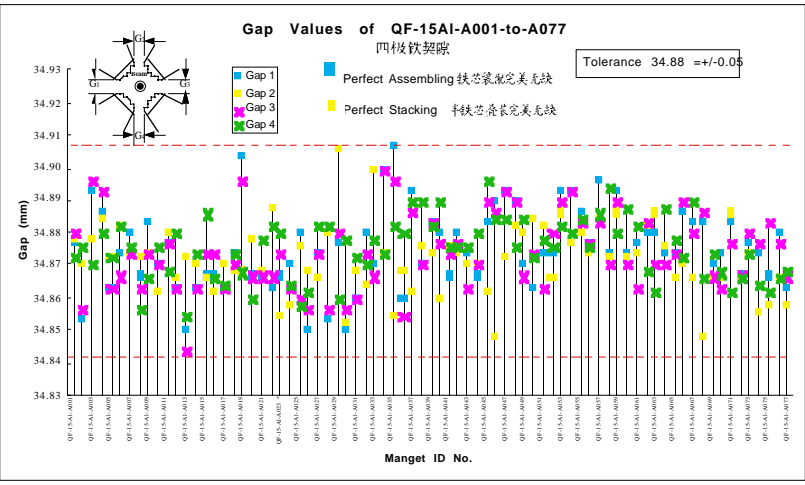

Figure 2: Gap Values of 77 Quadrupoles

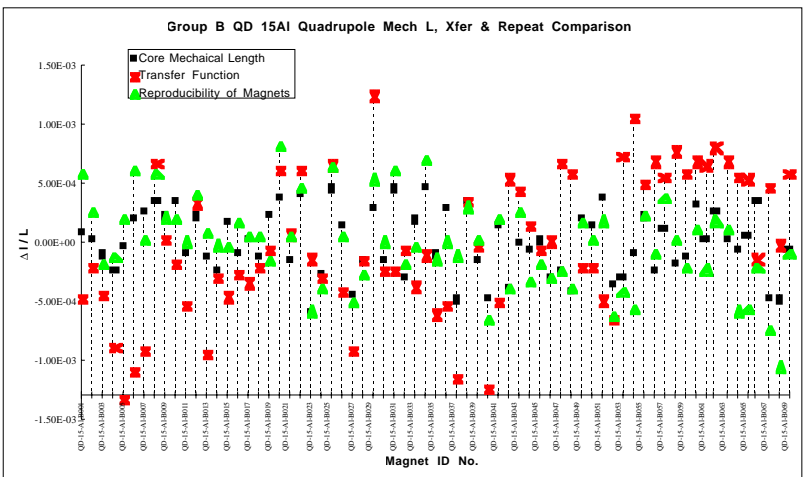

Figure 3: Mechanical Length, Transfer Function \& Reproducibility Comparison of 69 B Group Quadrupoles

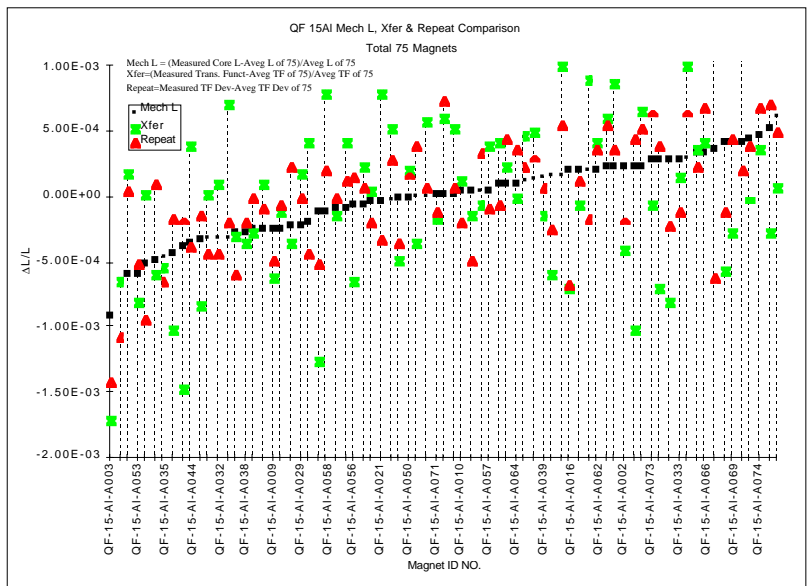

Figure 4: Mechanical Length, Transfer Function \& Reproducibility Comparison of 75 Quadrupoles 


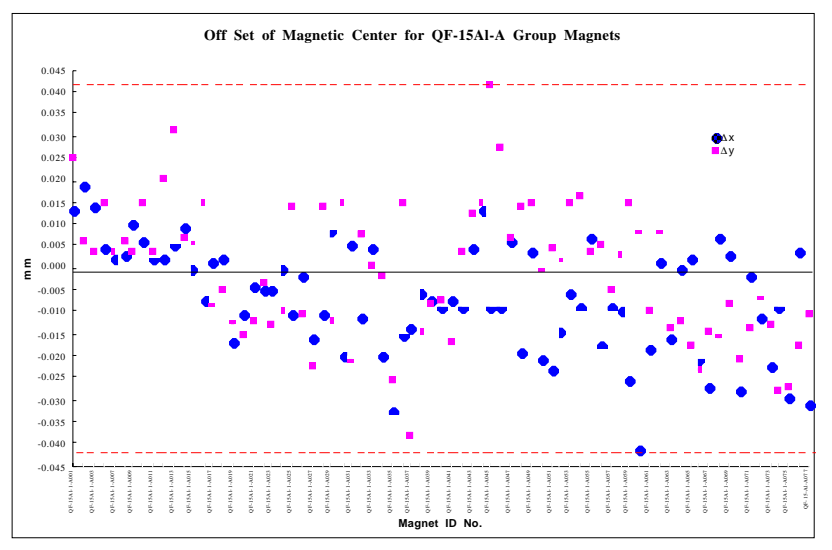

Fig. 5 A Group Quadrupole Magnetic Center Off Set

\section{REFERENCES}

1. J. Tanabe, J. Osborn, N. Li, D. Yee, Standard $43 \mathrm{~cm}$ Quadrupole Engineering Design, LBNL Mechanical Engineering Note M7498A, October, 1994 